\title{
3,6-Di(pyridin-2-yl) pyridazine derivatives as original and new corrosion inhibitors in support of mild steel: Experimental studies and DFT investigational
}

\section{Filali, ${ }^{1}$ E.M. El Hadrami, ${ }^{1}$ A. Ben-tama, ${ }^{1}$ B. Hafez, ${ }^{2}$ I. Abdel-Rahman, ${ }^{2}$ A. Harrach, ${ }^{3}$ H. Elmsellem, ${ }^{4}$ B. Hammouti, ${ }^{4}$ M. Mokhtari, ${ }^{5}$ SE. Stiriba ${ }^{6}$ and M. Julve 6}

${ }^{1}$ Laboratoire de Chimie Organique Appliquée, Université Sidi Mohamed Ben Abdellah, Faculté des Sciences et Techniques, Route d'Immouzer, BP 2202 Fès, Morocco

${ }^{2}$ Department of Chemistry, College of Sciences, University of Sharjah, PO Box: 27272, UAE

${ }^{3}$ Laboratoire de Chimie de la matière condensée, Université Sidi Mohamed Ben Abdellah,

Faculté des Sciences et Techniques, Route d'Immouzer, BP 2202 Fès, Morocco

${ }^{4}$ Laboratoire de chimie analytique appliquée, matériaux et environnement (LC2AME),

Faculté des Sciences, B.P. 717, 60000 Oujda, Morocco

${ }^{5}$ University of Echahid Hamma Lakhdar, PO Box 789, El-Oued, Algeria

${ }^{6}$ Instituto de Ciencia Molecular (ICMol), Université de Valencia, Spain

*E-mail: h.elmsellem@gmail.com

\begin{abstract}
Corrosion inhibition performance of three new synthesized novel compounds namely, 1-((3,6di(pyridin-2-yl)pyrdazin-4-yl)methyl)-indoline-2,3-dione (FM1), 4-(morpholinomethyl)-3,6di(pyridin-2-yl)pyridazine (FM2) and 3,6-di(pyridin-2-yl)-4-(p-tolyl)-pyridazine (FM3) on mild steel (MS) was investigated by $\mathrm{HCl}$ with $1 \mathrm{M}$ concentration. The corrosion inhibition performance of the synthesized compounds was studied by weight loss, impedance spectroscopy(EIS) and potentiodynamic polarization (PDP) methods. The results showed that the corrosion inhibition efficiency increases with the increase in the concentration of the compounds (FMs). The PDP measurements reveal that the type of these compounds is a mixed-type behavior. The results of impedance studies (EIS) showed that in the presence of FMs, the $R_{\mathrm{ct}}$ values increase while the $C_{\mathrm{dl}}$ values decrease due to the adsorption of inhibitors (FMs) on the mild steel surface. EIS study showed that there is one capacitance loop related to charge transfer mechanism. The adsorption of (FMs) on the mild steel surface obeys the Langmuir-adsorption isotherm. The 1-((3,6-di(pyridin-2-yl)pyrdazin-4-yl)methyl)-indoline2,3-dione (FM1) showed a better inhibition performance in comparison with the FM2 and FM3. The theoretical results which shows also a good correlation with the electrochemical experiments and weight loss measurements.
\end{abstract}

Key words: 3,6-di(pyridin-2-yl)pyridazine, mild steel, corrosion inhibitor, quantum chemical calculations. 


\section{Introduction}

Given their importance in the pharmaceutical, chemical and industrial fields, the synthesis of 3,6-di(pyridin-2-yl)pyridazine and its derivatives is a goal of the chemist in the last years. The systems containing this moiety also showed remarkable corrosion inhibitory [1-3].

Mild steels the most common type among steels due to its exceptional mechanical properties and reduced price [4]. It has low carbon content (up to 0.3\%) and it is used where large amounts of steel are necessary, and has found applications in many oil and gas industries for casing the down hole and in transmission pipelines [5]. The MS is very reactive as it reverts back to iron oxide when water, oxygen and ions are present [6], thus they are more vulnerable to corrosion which leads to great waste of natural resources and even causes potential risks. Further continual usage of hydrochloric acid and sulphuric acid for various industrial processes such as iron pickling, descaling practice in boilers, acidification of oil well in petroleum explorations [7,8]. In this revision the corrosion inhibition of three new synthesized compounds of 3,6-di(pyridin-2-yl)pyridazine derivatives (FMs) in $1.0 \mathrm{M} \mathrm{HCl}$ solution for MS was investigated.

Gravimetry, potentiodynamic polarization and electrochemical impedance spectroscopy techniques were used DFT calculations were used to understand the impact of molecular and electronic properties of the synthesized inhibitors (FMs) over MS surface and to find the most active inhibitor/MS contact dynamic sites. The molecular structure of the three new synthesized inhibitors (FMs) are shown in Figure 1.

FM1

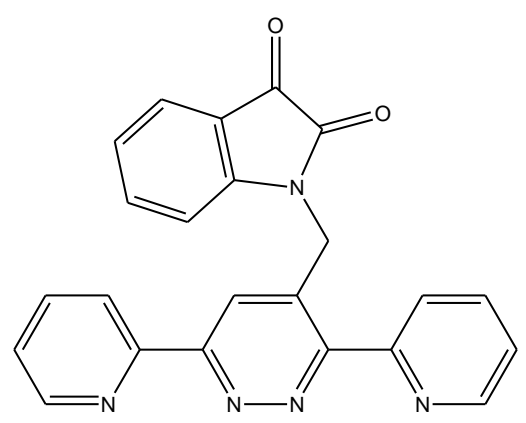

FM2

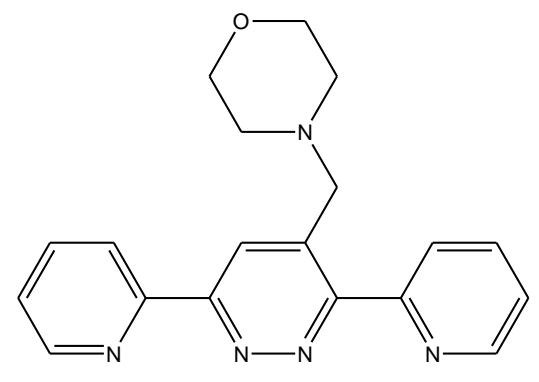

FM3

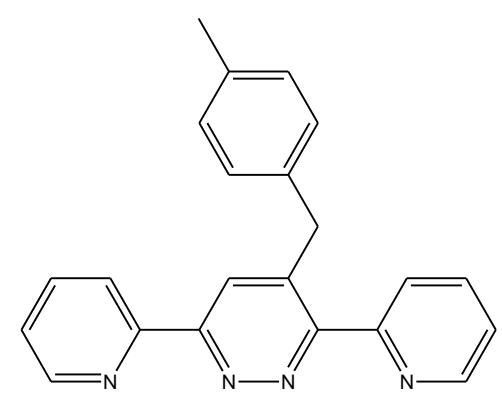

Figure 1. Molecular structure of the three new synthesized inhibitors (FMs).

\section{Experimental procedure}

\subsection{Synthesis of inhibitors (FMs)}

In this work, the formation of novel aromatic nitrogen heterocyclic compounds was done by thermal cycloaddition method (Diels-Alder reaction) as follows. 


\section{Step 1:}

$20 \mathrm{ml}$ of DMF, $12 \mathrm{mmol}$ of (isatin or morpholine), 1.5 eq. of potassium carbonate $\left(\mathrm{K}_{2} \mathrm{CO}_{3}\right)$ and $10 \%$ of BTBA were added in a conical flask and stirred for 10 minutes at room temperature. Then 1.2 eq. of propargyl bromide was added to the reaction mixture and stired for 48 hours After that, the solvent was evaporated and then the required organic compound was obtained by liquid-liquid extraction using dichloromethane. The organic phase was dried with sodium sulfate $\left(\mathrm{Na}_{2} \mathrm{SO}_{4}\right)$, and then evaporated. The corresponding pure products were obtained by purification using recrystallization in the mixture (Dichloromethane/hexane).

\section{Step 2:}

Into a flask, $4 \mathrm{mmol}$ of 3,6-bis(2-pyridyl)-1,2,4,5-tetrazine was dissolved in $20 \mathrm{ml}$ of toluene and then 1 eq. of appropriate alkyne was added and the reaction mixture was stirred and refluxed at temperatures between $210^{\circ} \mathrm{C}$ and $270^{\circ} \mathrm{C}$. After that, the solvent was evaporated. Column chromatography using silica gel as a stationary phase was used to obtain the corresponding pure products as shown in Scheme 1.

\subsection{Characterization of compounds}

\section{1-((3,6-Di(pyridin-2-yl)pyridazin-4-yl)methyl)indoline-2,3-dione (FM1)}

IR: $v\left(\mathrm{~cm}^{-1}\right): 1437$ (intense amide band $\left.\mathrm{RCONR}_{2}\right) ; 1600-1730(\mathrm{C}=\mathrm{C}$ aromatic).

NMR ${ }^{1} \mathrm{H}\left(\mathrm{CDCl}_{3}\right), \delta: 5.66 \mathrm{ppm}(\mathrm{s}, 2 \mathrm{H}) ; 6.81 \mathrm{ppm}(\mathrm{d}, 1 \mathrm{H}, J=8 \mathrm{~Hz}) ; 7.16 \mathrm{ppm}(\mathrm{t}, 1 \mathrm{H}, J=$ $7.5 \mathrm{~Hz}) ; 7.38 \mathrm{ppm}\left(\mathrm{dd}, 1 \mathrm{H}, J_{3}=7.4, J_{4}=4.9 \mathrm{~Hz}\right) ; 7.45-7.54 \mathrm{ppm}(\mathrm{m}, 2 \mathrm{H}) ; 7.7 \mathrm{ppm}(\mathrm{d}, 1 \mathrm{H}$, $J=7.4 \mathrm{~Hz}) ; 7.89 \mathrm{ppm}\left(\mathrm{td}, 1 \mathrm{H}, J_{3}=7.7 \mathrm{~Hz}, J_{4}=1 \mathrm{~Hz}\right) ; 8 \mathrm{ppm}\left(\mathrm{td}, 1 \mathrm{H}, J_{3}=7.7 \mathrm{~Hz}, J_{4}=\right.$ $1 \mathrm{~Hz}) ; 8.48 \mathrm{ppm}(\mathrm{s}, 1 \mathrm{H}) ; 8.5 \mathrm{ppm}(\mathrm{d}, 1 \mathrm{H}, J=9.6 \mathrm{~Hz}) ; 8.63 \mathrm{ppm}\left(\mathrm{dd}, 1 \mathrm{H}, J_{3}=4.8 \mathrm{~Hz}, J_{4}=\right.$ $0.7 \mathrm{~Hz}) ; 8.73 \mathrm{ppm}(\mathrm{d}, 1 \mathrm{H}, J=4.9 \mathrm{~Hz}) ; 8.76 \mathrm{ppm}\left(\mathrm{dd}, 1 \mathrm{H}, J_{3}=4.7 \mathrm{~Hz}, J_{4}=0.7 \mathrm{~Hz}\right)$.

\section{4-(Morpholinomethyl)-3,6-di(pyridin-2-yl)pyridazine (FM2)}

IR: $v\left(\mathrm{~cm}^{-1}\right)$ : 915-1108 (cyclic ether $\left.\mathrm{C}-\mathrm{O}-\mathrm{C}\right) ; 1578-1657$ ( $\mathrm{C}=\mathrm{C}$ aromatic).

$\operatorname{NMR}{ }^{1} \mathrm{H}\left(\mathrm{CDCl}_{3}\right), \delta: 2.46 \mathrm{ppm}(\mathrm{t}, 4 \mathrm{H}, J=4.2 \mathrm{~Hz}) ; 3.66 \mathrm{ppm}(\mathrm{t}, 4 \mathrm{H}, J=4.2 \mathrm{~Hz}) ; 4.10 \mathrm{ppm}$ $(\mathrm{s}, 2 \mathrm{H}) ; 7.42 \mathrm{ppm}\left(\mathrm{dd}, 1 \mathrm{H}, J_{3}=12.5, J_{4}=5.2 \mathrm{~Hz}\right) ; 7.89-7.96 \mathrm{ppm}(\mathrm{m}, 2 \mathrm{H}) ; 8.18 \mathrm{ppm}(\mathrm{d}$, $1 \mathrm{H}, J=7.8 \mathrm{~Hz}) ; 8.71-8.73 \mathrm{ppm}(\mathrm{m}, 3 \mathrm{H}) ; 8.74 \mathrm{ppm}(\mathrm{s}, 1 \mathrm{H})$.

\section{3,6-Di(pyridin-2-yl)-4-(p-tolyl)pyridazine (FM3)}

IR: $v\left(\mathrm{~cm}^{-1}\right): 1570(\mathrm{C}=\mathrm{C}$ aromatic $) ; 2930\left(\mathrm{CH}_{3}-\mathrm{Ph}\right)$.

NMR ${ }^{1} \mathrm{H}\left(\mathrm{CDCl}_{3}\right), \delta: 2.34 \mathrm{ppm}(3 \mathrm{H}, \mathrm{s}) ; 7.1-7.18(4 \mathrm{H}, \mathrm{m}) ; 7.26-7.3 \mathrm{ppm}(1 \mathrm{H}, \mathrm{m})$; $7.40 \mathrm{ppm}\left(1 \mathrm{H}, \mathrm{dd}, J_{3}=7.6, J_{4}=4.8 \mathrm{~Hz}\right) ; 7.76-7.94 \mathrm{ppm}(3 \mathrm{H}, \mathrm{m}) ; 8.50 \mathrm{ppm}(\mathrm{d}, 1 \mathrm{H}, J=$ $3.9 \mathrm{~Hz}) ; 8.65 \mathrm{ppm}(1 \mathrm{H}, \mathrm{s}) ; 8.75 \mathrm{ppm}(\mathrm{d}, 1 \mathrm{H}, J=3.3 \mathrm{~Hz}) ; 8.79 \mathrm{ppm}(\mathrm{d}, 1 \mathrm{H}, J=7.2 \mathrm{~Hz})$.

\subsection{Materials}

The composition of MS is as follows (wt.\%): C 0.076, Mn 0.192, P 0.012, Si 0.026, $\mathrm{Cr} 0.050, \mathrm{Al} 0.023$, and the remaining iron $(\mathrm{Fe})$ element. The MS specimens having the following dimensions: $1.5,1.5$, and $0.5 \mathrm{~cm}$ were used for all gravimetric measurements. The examined MS coupons were ground through emery papers $(\mathrm{SiC})$ of different grades 
$(120,240,320,400,600$ and 1200). After polishing, the MS coupons were washed with double distilled water and acetone before using.

Electrochemical measurements: the tested MS coupons for the electrochemical measurements were cylindrical with $1 \mathrm{~cm}^{2}$ surface area.

The $1.0 \mathrm{M} \mathrm{HCl}$ solution was prepared via dilution of the analytical $\mathrm{HCl}$ solution (Sigma Aldrich, 37\%) using double distilled water. Four different concentrations $\left(10^{-3}\right.$ to $10^{-6} \mathrm{M}$ ) of the studied FM inhibitors were prepared in $10 \mathrm{HCl}$ solution.

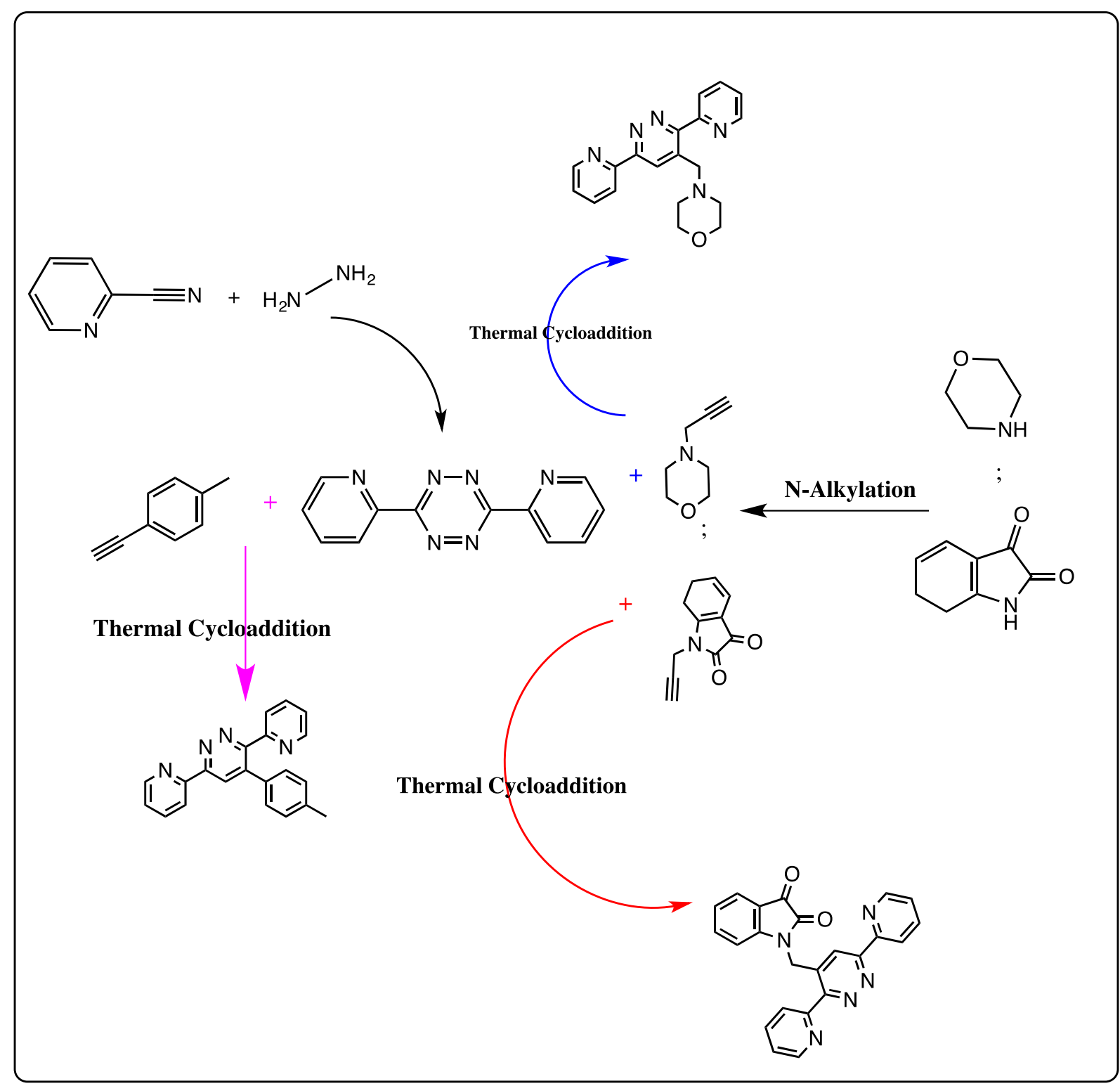

Scheme 1. The synthesis of the three new inhibitors (FMs). 


\subsection{Weight loss}

Weight loss measurements were performed by the immersion of the MS coupons in $1.0 \mathrm{M}$ $\mathrm{HCl}$ solutions with various concentrations of FMs for 6 hours at $308 \mathrm{~K}$. The MS coupons were weighed prior to immersion.

The weight loss measurements were done in triplicate and the mean value was reported to assure the reproducibility.

The percentage inhibition efficiency $\left(\eta_{\mathrm{w}} \%\right)$ was calculated using the following equation [9]:

$$
\begin{gathered}
\eta_{\mathrm{W}} \%=\frac{w_{0}-w_{\mathrm{i}}}{w_{0}} \times 100 \\
\eta_{\mathrm{W}} \%=\theta \times 100
\end{gathered}
$$

where $w_{0}$ and $w_{\mathrm{i}}$ are the weight of MS coupon in the uninhibited and inhibited solutions, respectively, and $\theta$ is the surface coverage of MS.

\subsection{Electrochemical measurements}

The effect of the studied inhibitors (FMs) on the MS corrosion in $1.0 \mathrm{M} \mathrm{HCl}$ solutions was studied using electrochemical techniques: electrochemical impedance spectroscopy and potentiodynamic polarization. The concentration range of the FM inhibitors was between $\left(10^{-6}\right.$ to $\left.10^{-3}\right) \mathrm{M}$ and at a temperature of $308 \mathrm{~K}$.

The electrochemical experiment consisted of an electrolytic cell consisting of three electrodes. The platinum foil acts as the counter electrode, the saturted calomel acts as the reference electrode and the MS cylinder acts as the working electrode with an exposed surface area of one $\mathrm{cm}^{2}$.

The MS specimen was immersed in the tested solution for 05 hour until a steady state potential was achieved using a potentiostat of PGZ100 type. Electrochemical impedance spectroscopy measurements were performed with a frequency range of $100 \mathrm{Khz}$ to $10 \mathrm{mhz}$ and amplitude of $10 \mathrm{mV}$ with 10 points per decade.

The potentiodynamic polarization curves were recorded by polarization with a scan rate of $2 \mathrm{mV} / \mathrm{s}$.

\section{Results and Discussions}

\subsection{Weight loss measurements}

Corrosion rates, inhibition efficiencies and the surface coverage values for MS in $1.0 \mathrm{M}$ $\mathrm{HCl}$ solution with different concentrations of FM1, MF2 and MF3 were calculated using equations (1 and 2).

The values of corrosion rates and inhibition efficiencies are presented in Table 1. It is evident from Table 1 that the corrosion rate significantly decreased from $0.82 \mathrm{mg} \cdot \mathrm{cm}^{-2} \mathrm{~h}^{-1}$ in the blank (uninhibited) $1.0 \mathrm{M} \mathrm{HCl}$ solution to $0.11 \mathrm{mg} \cdot \mathrm{cm}^{-2} \mathrm{~h}^{-1}$ for FM1, $0.23 \mathrm{mg} \cdot \mathrm{cm}^{-2} \mathrm{~h}^{-1}$ 
for FM2 and $0.25 \mathrm{mg} \cdot \mathrm{cm}^{-2} \mathrm{~h}^{-1}$ for FM3 when $10^{-3} \mathrm{M}$ of these inhibitors were added to $1.0 \mathrm{M} \mathrm{HCl}$ solutions.

The high corrosion inhibition efficiency of the investigated MFs compounds is attributed to the presence of $(\mathrm{N}, \mathrm{O})$ atoms and the $\pi$-electrons, which act as adsorption centers and can effectively cover the surface of MS. The higher inhibition efficiency of the FM1 compared to FM2 and FM3 is attributed to the presence of more $\pi$-electrons (benzyl group) and $\mathrm{O}$ atoms.

Table 1. The corrosion rates, inhibition efficiencies and the surface coverage of the studied FMs inhibitors for MS in $1.0 \mathrm{M} \mathrm{HCl}$ solutions at $308 \mathrm{~K}$.

\begin{tabular}{ccccc}
\hline Inhibitor & $\begin{array}{c}\text { Inhibitor } \\
\text { concentration } \\
(\mathbf{m o l} / \mathbf{l})\end{array}$ & $\begin{array}{c}\boldsymbol{C}_{\mathbf{R}} \\
\left(\mathbf{m g} \cdot \mathbf{c m}^{-2} \mathbf{h}^{-\mathbf{1}}\right)\end{array}$ & $\boldsymbol{\eta}_{\mathbf{w}}(\boldsymbol{\%})$ & $\boldsymbol{\theta}$ \\
\hline- & - & 0.82 & - & - \\
& $10^{-6}$ & 0.39 & 52 & 0.52 \\
FM1 & $10^{-5}$ & 0.32 & 61 & 0.61 \\
& $10^{-4}$ & 0.21 & 74 & 0.74 \\
& $10^{-3}$ & 0.11 & 87 & 0.87 \\
\hline \multirow{2}{*}{ FM2 } & $10^{-6}$ & 0.45 & 45 & 0.45 \\
& $10^{-5}$ & 0.41 & 50 & 0.50 \\
& $10^{-4}$ & 0.34 & 59 & 0.59 \\
& $10^{-3}$ & 0.23 & 72 & 0.72 \\
FM3 & $10^{-6}$ & 0.51 & 38 & 0.38 \\
& $10^{-5}$ & 0.44 & 46 & 0.46 \\
& $10^{-4}$ & 0.36 & 56 & 0.56 \\
& $10^{-3}$ & 0.25 & 70 & 0.70 \\
\hline
\end{tabular}

\subsection{Adsorption isotherm}

The adsorption isotherm describes the type of interaction between the molecules of the inhibitors (FM1, FM2 and FM3) and the MS surface. The FMs molecules adsorb on $\mathrm{MS} /$ solution interface by the dislocation of water molecules as shown [10]:

$$
\mathrm{FM}_{\mathrm{sol}}+x \mathrm{H}_{2} \mathrm{O}_{\mathrm{ads}} \rightarrow \mathrm{FM}_{\mathrm{ads}}+x \mathrm{H}_{2} \mathrm{O}_{\text {sol }}
$$

Where, $x$ is the number of water molecules replaced from the MS surface by one molecule of each inhibitor (FM1, FM2 and FM3). The surface coverage values of MS (Table 1) were used to fit diverse commonly used adsorption isotherms such as Temkin, Freundlich and Langmuir adsorption isotherms. The Langmuir adsorption isotherm gave the best fit in the 
current study. The Langmur adsorption isotherm can be represented by the following equation:

$$
\frac{C}{\theta}=\frac{1}{K_{\text {ads }}}+C
$$

where, $C$ is the concentration of the inhibitor, $\theta$ is the surface coverage and $K_{\text {ads }}$ is the adsorption equilibrium constant. The plot of $C / \theta$ vs. $C$ (optimum concentration of FM molecules) gave a straight line with regression coefficient $\left(R^{2}\right)$ values near to one at $308 \mathrm{~K}$ (Figure 2). The slopes of the straight lines are unity, which indicates that FM molecules form a monolayer on the MS surface [11]. The values of $K_{\text {ads }}$ were derived from the intercept $\left(1 / K_{\text {ads }}\right)$ and using the value of $K_{\text {ads }}, \Delta G_{\text {ads }}$ values were calculated using the following equation $[12,13]$

$$
\Delta G_{\mathrm{ads}}=-R T \ln (55.5 K)
$$

where, $T$ is the experimental temperature in Kelvin, $R$ is the universal gas constant and 55.5 is the concentration of water in acid solution in M. The parameters of adsorption $K_{\text {ads }}$, $\Delta G_{\text {ads }}$ are presented in Table 2 . The negative values of free energy of adsorption $\left(\Delta G_{\text {ads }}\right)$ indicated that the studied inhibitors are spontaneously adsorbed on the MS surface [14]. In general, values of free energy of adsorption $\left(\Delta G_{\mathrm{ads}}\right)$ around $-20 \mathrm{~kJ} / \mathrm{mol}$ or less negative are associated with the electrostatic interaction between the opposite charge of FM molecules and MS (physorption) and free energy of adsorption values around $-40 \mathrm{~kJ} \cdot \mathrm{mol}^{-1}$ or more negative are related to sharing or transferring of electrons between the FMs molecules and MS to form a covalent type bond (chemisorption) [15, 16].

In the present work, the values of the free energy of adsorption $\left(\Delta G_{\mathrm{ads}}\right)$ for all FMs inhibitors ranges from -37.99 to $-39.34 \mathrm{~kJ} \cdot \mathrm{mol}^{-1}$ which are more close to $-40 \mathrm{~kJ} \cdot \mathrm{mol}^{-1}$ which indicate that the adsorption of the inhibitors (FMs) on the MS surface is mainly chemisorption process [17].

Table 2. The values of $K_{\text {ads }}$ and $\Delta G_{\text {ads }}$ of FMs inhibitors for MS in $1.0 \mathrm{M} \mathrm{HCl}$ solution at $308 \mathrm{~K}$.

\begin{tabular}{cccc}
\hline Inhibitors & $\boldsymbol{K}_{\text {ads }}(\mathbf{1 0} / \mathbf{M})$ & $\Delta \boldsymbol{G}_{\text {ads }}(\mathbf{k J} / \mathbf{m o l})$ & $\boldsymbol{R}^{\mathbf{2}}$ \\
\hline FM1 & 11.8 & 39.34 & 0.99 \\
FM2 & 8.14 & 38.41 & 0.99 \\
FM3 & 6.88 & 37.99 & 0.99 \\
\hline
\end{tabular}




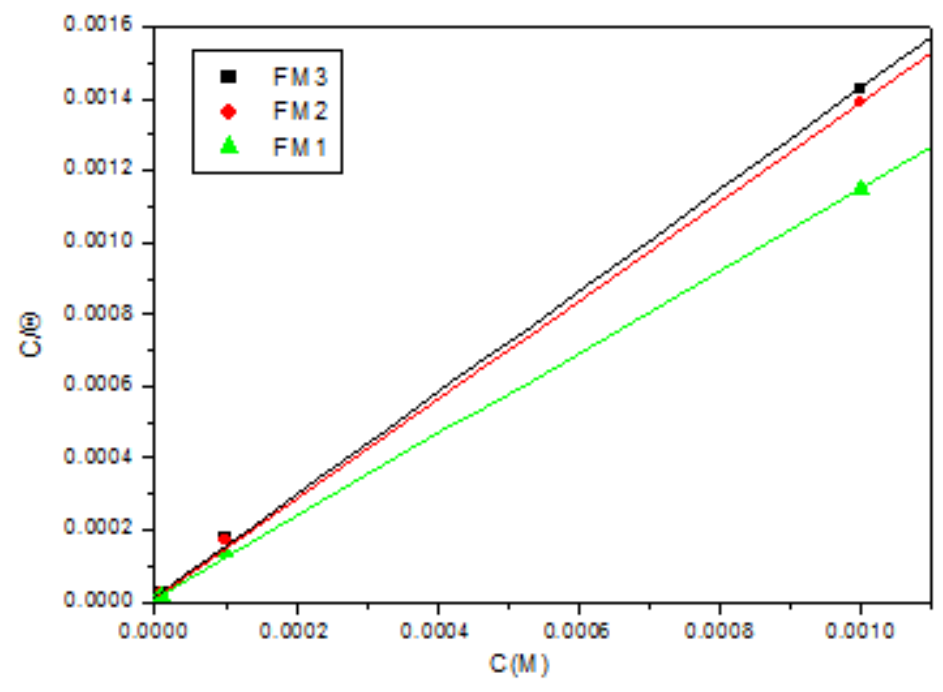

Figure 2. Langmuir isotherm plot for the adsorption of the studied inhibitors (FMs) on the MS surface in $1.0 \mathrm{M} \mathrm{HCl}$ solutions.

\subsection{Potentiodynamic polarization measurements}

The MS potentiodynamic polarization curves in various concentrations of inhibitors (FMs) are shown in Figure 3.

The electrochemical parameters of the tested inhibitors (FMs) were acquired by extrapolating slopes of Tafel plots with corrosion potential $\left(E_{\text {corr }}\right)$. These parameters are grouped together in Table 3.

The inhibitor efficiency $\left(E_{I} \%\right)$ values were calculated from the corrosion current densities using the following equation:

$$
E_{I} \%=\left(1-\frac{I_{\text {corr }}}{I_{\text {corr }}^{0}}\right) \times 100
$$

Where $I_{\text {corr }}^{0}$ is the corrosion current density in $1.0 \mathrm{M} \mathrm{HCl}$ solution without inhibitor (blank) and $I_{\text {corr }}$ is the corrosion current density in $1.0 \mathrm{M} \mathrm{HCl}$ solution with one of the inhibitors (FMs).

The electrochemical parameters data are tabulated in Table 3. The results showed that, as the concentration of inhibitors (FMs) increased, the $I_{\text {corr }}$ values decreased. The addition of various concentrations of FMs inhibitors causes slight variations in the cathodic Tafel slopes $\left(\beta_{\mathrm{c}}\right)$ as presented in Table 3 , indicating that $(\mathrm{FMs})$ inhibitors are cathodic inhibitors.

Considering the maximum change in $E_{\text {corr }}$ values was $-18 \mathrm{mV}$ which was far less than the $\pm 85 \mathrm{mV}$ indicates that the inhibitors (FMs) behave as mixed-type inhibitors but predominantly cathodic inhibitors. This suggests that the inhibitors (FMs) do not interfere only with the evolution of hydrogen but also interfere with the anodic reaction [18]. 

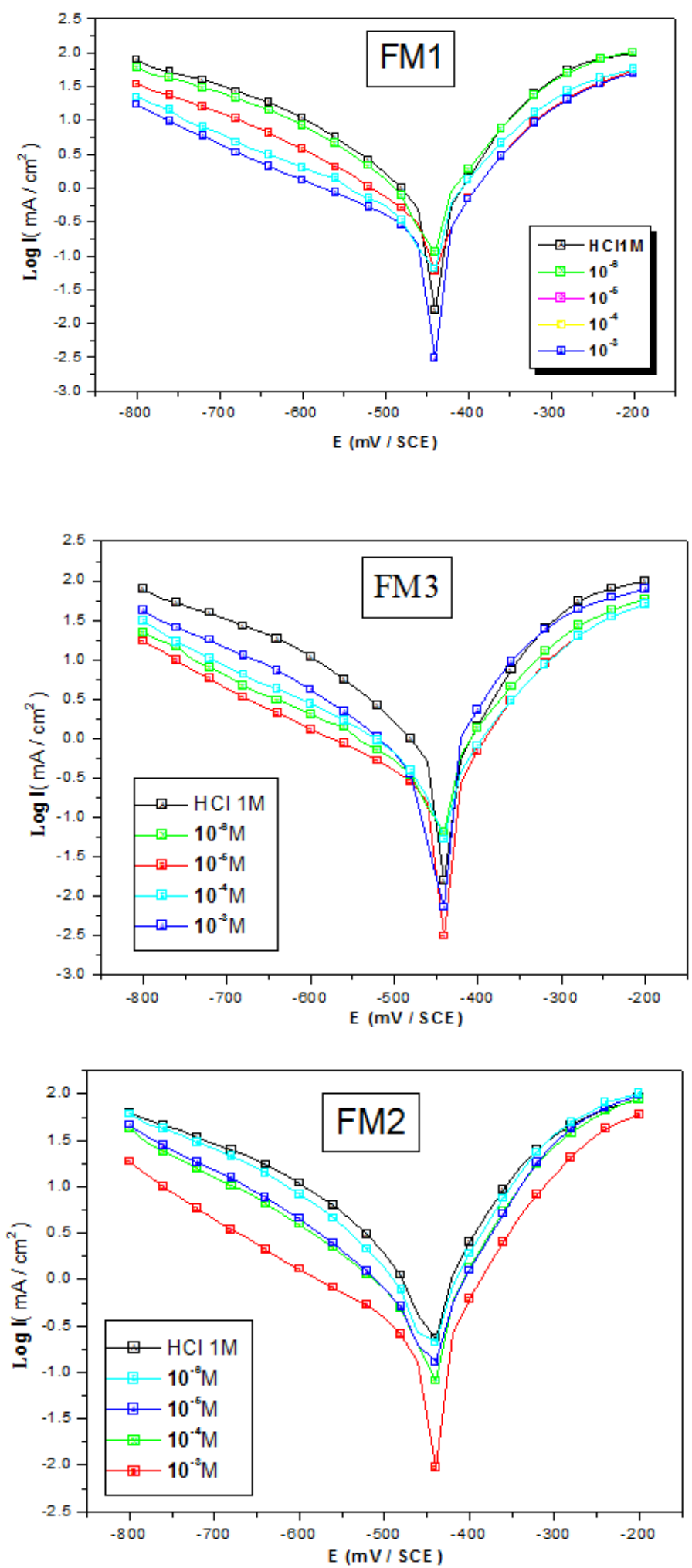

Figure 3. Polarization curves for MS in the absence and presence of different concentrations of inhibitors (FMs) in $1.0 \mathrm{M} \mathrm{HCl}$ solutions at $308 \mathrm{~K}$. 
Table 3. Potentiodynamic polarization parameters for $\mathrm{MS}$ in $1.0 \mathrm{M} \mathrm{HCl}$ solution in the absence and presence of various concentrations of inhibitors (FMs) at $308 \mathrm{~K}$.

\begin{tabular}{ccccccc}
\hline Inhibitor & $\begin{array}{c}\text { Concentration } \\
(\mathbf{M})\end{array}$ & $\begin{array}{c}\boldsymbol{E}_{\mathbf{c o r}} \\
(\mathbf{m v} / \mathbf{E C S})\end{array}$ & $\begin{array}{c}-\boldsymbol{\beta}_{\mathbf{c}} \\
(\mathbf{m v} / \mathbf{d e c})\end{array}$ & $\begin{array}{c}\boldsymbol{\beta a} \\
(\mathbf{m v} / \mathbf{d e c})\end{array}$ & $\begin{array}{c}\boldsymbol{I}_{\mathbf{c o r}} \\
\left(\boldsymbol{\mu} \mathbf{A} \cdot \mathbf{c m}^{-2}\right)\end{array}$ & $\boldsymbol{E}_{\boldsymbol{I}} \boldsymbol{\%}$ \\
\hline Blank & - & -448 & 124 & 71 & 540 & - \\
\hline \multirow{3}{*}{ FM1 } & $10^{-6}$ & -449 & 117 & 68 & 277 & 49 \\
& $10^{-5}$ & -458 & 131 & 65 & 214 & 60 \\
& $10^{-4}$ & -447 & 150 & 67 & 125 & 77 \\
& $10^{-3}$ & -442 & 198 & 74 & 45 & 92 \\
\hline \multirow{3}{*}{ FM2 } & $10^{-6}$ & -451 & 122 & 70 & 355 & 34 \\
& $10^{-5}$ & -449 & 117 & 68 & 257 & 52 \\
& $10^{-4}$ & -462 & 163 & 62 & 176 & 67 \\
& $10^{-3}$ & -443 & 199 & 69 & 59 & 89 \\
\hline \multirow{3}{*}{ FM3 } & $10^{-6}$ & -448 & 137 & 69 & 433 & 19 \\
& $10^{-5}$ & -466 & 149 & 67 & 318 & 41 \\
& $10^{-4}$ & -455 & 138 & 65 & 262 & 51 \\
\hline
\end{tabular}

The increase in inhibition efficiency with the increase in the concentration of inhibitors (FMs) indicates that, the inhibitors molecules are adsorbed on the MS surface. The molecules of inhibitors (FMs) are adsorbed on the MS surface, therefore they block further corrosion reaction. The observed decrease in corrosion current densities, $I_{\text {corr }}$, with the increase in the concentration of inhibitors (FMs) in Table 3, indicates increased protection of the MS surface.

\subsection{Electrochemical Impedance Spectroscopy}

The Nyquist impedance curves for inhibitors (FM1, MF2 and MF3) in 1.0 M HCl solutions with various concentrations are shown in Figure 4.

The Nyquist plot has a semi-circular loop over the entire frequency range, which can be attributed to the charge transfer that occurred between the molecules of inhibitors (FMs) and the MS surface in the $1.0 \mathrm{M} \mathrm{HCl}$ solution [19].

The imperfect semicircular nature of the capacitive loops could be explained by the inhomogeneity's of the MS surface and the roughness of the tapped pieces.

The diameter of the capacitive loop increases with increasing concentration of FMs inhibitors. This marked increase in the diameter of their capacitive loop with the increase of concentration of the inhibitors, implies that the inhibition efficacy of the inhibitors is proportional to their concentration [20]. 
Increasing the concentration of the inhibitors (FMs) increases the rate of interaction between the $\mathrm{N}$ atoms in FMs and the Fe atoms in MS surface at the active sites leading to adsorption of the molecules of (FMs) on the MS surface [21].

This indeed suggests that, $\mathrm{N}$ atoms form a coordination bond with the Fe atoms in the MS surface. The aromatic system can also give $\pi$-electrons to the MS surface, which improves adsorption of the inhibitor molecules on the MS surface and increases the power of the inhibition efficiency of the inhibitors (FMs) [22].

Double layer capabilities have shown that the corrosion mechanism is mainly controlled by charge transfer processes.

The Impedance Spectroscopy (EIS) parameters obtained from the Nyquist diagrams are summarized in Table 4. As presented in Table 4, the charge transfer resistance $\left(R_{\mathrm{ct}}\right)$ values increased significantly when FMs inhibitors were added and continuously increased with increasing concentration leading to an increase in inhibition efficiency.

On the other hand, the double layer decreased with the increase of inhibitor concentration. Changes in $R_{\mathrm{ct}}$ values may be due to the FMs molecules that adsorbed on the MS surface instead of water, therefore reducing the active sites exposed for corrosion [23].
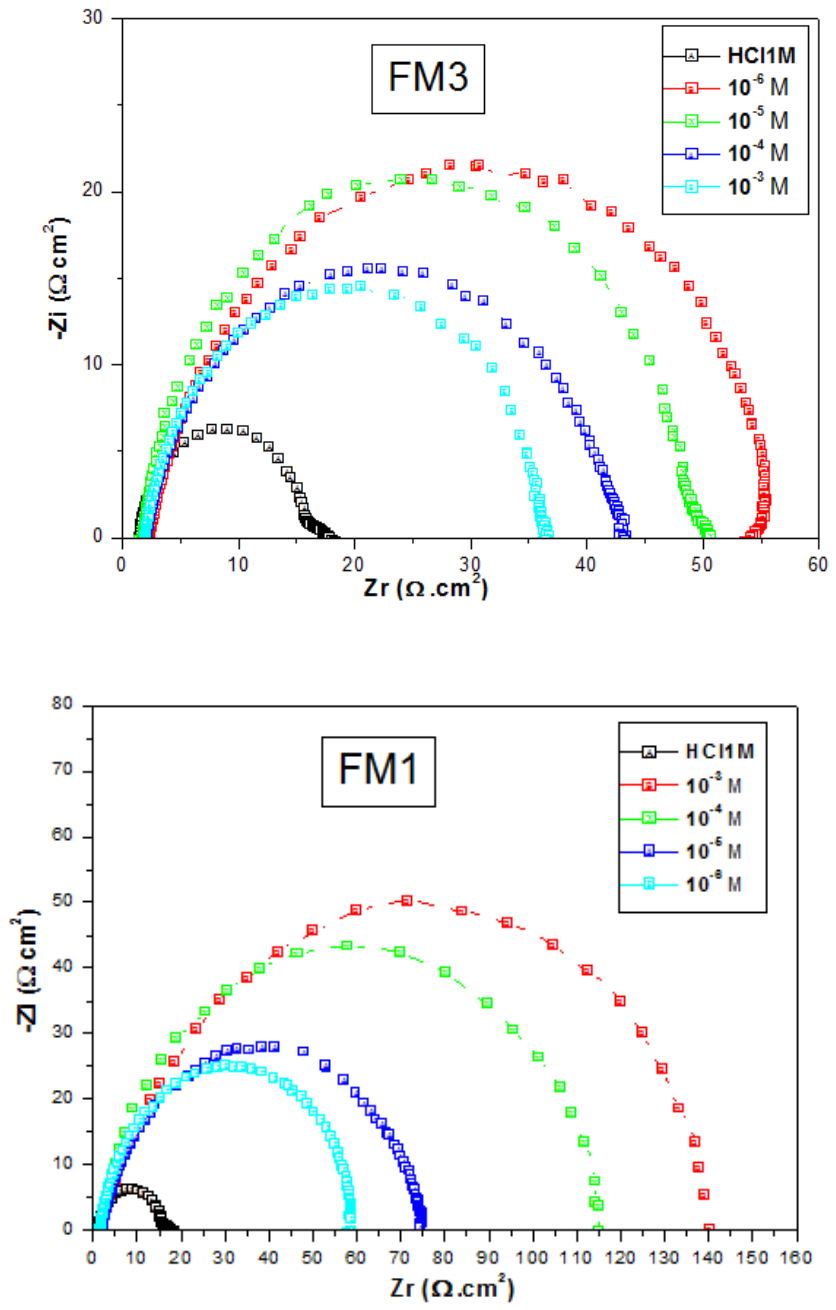


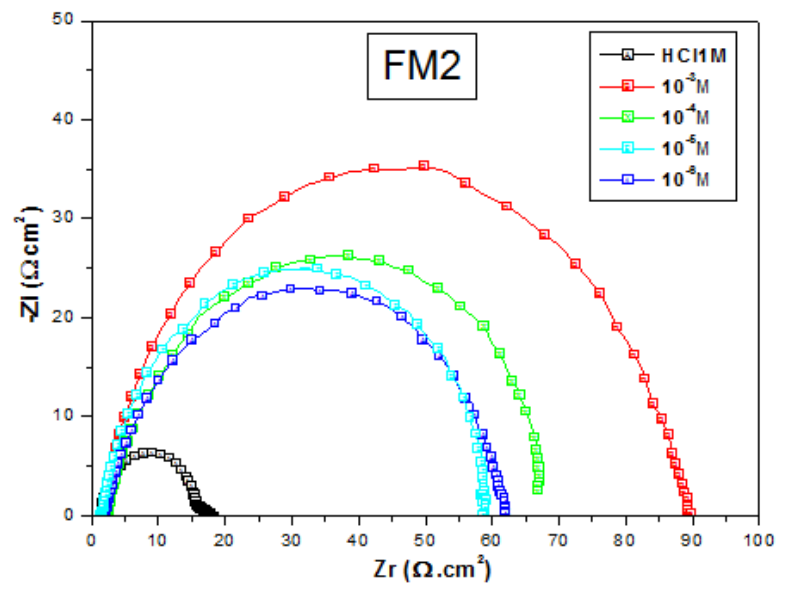

Figure 4. Nyquist plots for $\mathrm{MS}$ in $1.0 \mathrm{M} \mathrm{HCl}$ solutions without and with different concentrations of FMs at 308K.

Table 4. EIS parameters obtained for $\mathrm{MS}$ in $1.0 \mathrm{M} \mathrm{HCl}$ solutions in the absence and presence of different concentrations of FMs at $308 \mathrm{~K}$.

\begin{tabular}{ccccccc}
\hline Inhibitor & $\begin{array}{c}\text { Concentration } \\
(\mathbf{M})\end{array}$ & $\boldsymbol{R}_{\mathbf{S}}\left(\mathbf{\Omega} \mathbf{~ c m}^{2}\right)$ & $\boldsymbol{R} \mathbf{t}\left(\mathbf{\Omega} \mathbf{c m}^{\mathbf{2}}\right)$ & $\boldsymbol{f}(\mathbf{H z})$ & $\begin{array}{c}\mathbf{C}_{\mathbf{d l}} \\
\left(\boldsymbol{\mu} \mathbf{F} / \mathbf{c m}^{2}\right)\end{array}$ & $\boldsymbol{E} \%$ \\
\hline Blank & - & 1.37 & 14.57 & 54.64 & 200 & - \\
\hline \multirow{3}{*}{ FM1 } & $10^{-6}$ & 2.07 & 58 & 54.53 & 50.35 & 74 \\
& $10^{-5}$ & 2.63 & 77 & 52.35 & 33.78 & 81 \\
& $10^{-4}$ & 1.55 & 116 & 39.69 & 34.59 & 87 \\
& $10^{-3}$ & 1.79 & 142 & 33.20 & 80.29 & 90 \\
\hline \multirow{3}{*}{ FM2 } & $10^{-6}$ & 1.57 & 58 & 51.04 & 53.79 & 75 \\
& $10^{-5}$ & 2.21 & 62 & 52.24 & 49.16 & 76 \\
& $10^{-4}$ & 2.52 & 67 & 63.65 & 37.34 & 78 \\
& $10^{-3}$ & 1.72 & 94 & 52.46 & 32.29 & 84 \\
\hline \multirow{2}{*}{ FM3 } & $10^{-6}$ & 1.98 & 36.69 & 74.30 & 58.41 & 60 \\
& $10^{-5}$ & 1.97 & 42.69 & 68.62 & 54.36 & 65 \\
& $10^{-4}$ & 1.72 & 50.62 & 61.96 & 52.87 & 71 \\
\hline
\end{tabular}

\section{Theory and computational details}

In order to compare the experimental and theoretical results, a theoretical study was carried out using the Gaussian program. Ionization potential $(I)$ and electron affinity $(A)$ are related to $E_{\mathrm{HOMO}}$ and $E_{\mathrm{LUMO}}$ as follows $[24,25]$

$$
I=-E_{\mathrm{HOMO}}, A=-E_{\mathrm{LUMO}}
$$


The approximated equation for the absolute electronegativity $(\chi)$ and global hardness $(\eta)$ of the inhibitor molecule is as follows [26]:

$$
\begin{gathered}
\chi=\frac{I+A}{2}, \chi=-\frac{1}{2}\left(E_{\mathrm{HOMO}}+E_{\mathrm{LUMO}}\right) \\
\eta=\frac{I-A}{2}, \eta=-\frac{1}{2}\left(E_{\mathrm{HOMO}}-E_{\mathrm{LUMO}}\right)
\end{gathered}
$$

Where $I=-E_{\mathrm{HOMO}}$ and $A=-E_{\mathrm{LUMO}}$ are the ionization potential and electron affinity, respectively.

To evaluate the electronic flow in reaction of two systems with different electronegativities, in this particular case, a metallic surface $\mathrm{Fe}$ and an inhibitor molecule, we calculated the fraction of transferred electrons $\Delta N$ according to Pearson theory [27]. $\Delta N$ is given as follows:

$$
\Delta N=\frac{\chi_{\mathrm{Fe}}-\chi_{\mathrm{inh}}}{2\left(\eta_{\mathrm{Fe}}+\eta_{\mathrm{inh}}\right)}
$$

Where:

$\chi_{\mathrm{Fe}}$ : absolute electronegativity of an iron atom $(\mathrm{Fe})$;

$\chi_{\text {inh }}:$ absolute electronegativity of inhibitor molecule;

$\eta_{\mathrm{Fe}}$ : absolute hardness of Fe atom;

$\eta_{\text {inh }}$ : absolute hardness of inhibitor molecule.

Sastri et al. [28] have proposed the $(\omega)$ as a measure of energy lowering owing to maximal electron flow between donor and acceptor and $\omega$ is defined as follows:

$$
\omega=\frac{\chi^{2}}{2 \eta}
$$

The Softness $(\sigma)$ being the inverse of the $\eta[29]$ is as follows:

$$
\sigma=\frac{1}{\eta}
$$

The HOMO and LUMO orbital energies, gap, electrophilicity and chemical hardness-softness were obtained and tabulated in Table 5. The high ionization energy values for the FMs inhibitors $(I=7.20,7.09$ and $6.57 \mathrm{eV}$ for FM1, FM2 and FM3, respectively) indicates high stability.

Table 5. Quantum chemical descriptors of the studied compounds (FMs) at B3LYP / 6-31G(dp).

\begin{tabular}{cccccccccccc}
\hline $\begin{array}{c}\text { Inhi- } \\
\text { bitor }\end{array}$ & $\begin{array}{c}\boldsymbol{E}_{\text {HOMO }} \\
(\mathbf{e V})\end{array}$ & $\begin{array}{c}\mathbf{E}_{\mathrm{LUMO}} \\
(\mathbf{e V})\end{array}$ & $\begin{array}{c}\mathbf{G a p} \boldsymbol{\Delta} \boldsymbol{E} \\
(\mathbf{e V})\end{array}$ & $\boldsymbol{\mu}(\mathbf{D})$ & $\begin{array}{c}\mathbf{I P} \\
(\mathbf{e V})\end{array}$ & $\begin{array}{c}\mathbf{E A} \\
(\mathbf{e V})\end{array}$ & $\begin{array}{c}\boldsymbol{X} \\
(\mathbf{e V})\end{array}$ & $\boldsymbol{\eta}(\mathbf{e V})$ & $\boldsymbol{\omega}$ & $\boldsymbol{\sigma}$ & $\boldsymbol{\Delta} \boldsymbol{N}$ \\
\hline FM1 & -7.2017 & -1.5561 & 5.6455 & 4.6527 & 7.2017 & 1.5561 & 4.3789 & 2.8228 & 3.3965 & 0.3543 & 0.4643 \\
$\mathbf{F M 2}$ & -7.0917 & -0.4057 & 6.6860 & 2.6780 & 7.0917 & 0.4057 & 3.7487 & 3.3430 & 2.1018 & 0.2991 & 0.4863 \\
FM3 & -6.5777 & -0.3524 & 6.2254 & 4.3274 & 6.5777 & 0.3524 & 3.1127 & 3.1127 & 1.9287 & 0.4331 & 0.5678 \\
\hline
\end{tabular}


The number of transferred electrons from the inhibitor to the metal $(\Delta N)$ was also calculated. The $\Delta N<3.6$ indicates the tendency of a molecule to donate electrons to the metal surface [31]. As mentioned above, inhibition efficiency and $\Delta N$ are highly correlated. Hence, with respect to FM1, FM2 and FM3 inhibitors, the higher inhibition efficiency of FM1 compared to FM2 and FM3 is in good agreement with the increased $\Delta N$ values (0.4643, 0.4863 and 0.5678 for FM1, FM2 and FM3, respectively).

The final optimized geometries of FM1, FM2 and FM3, the selected valence bond angles, the selected dihedral angles and bond lengths are shown in Figure 5.

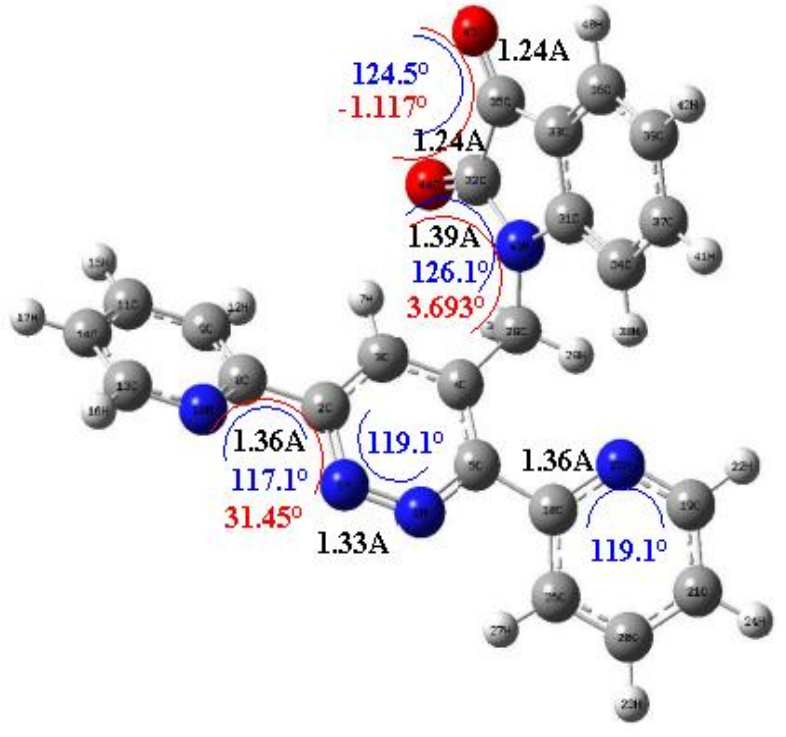

FM1

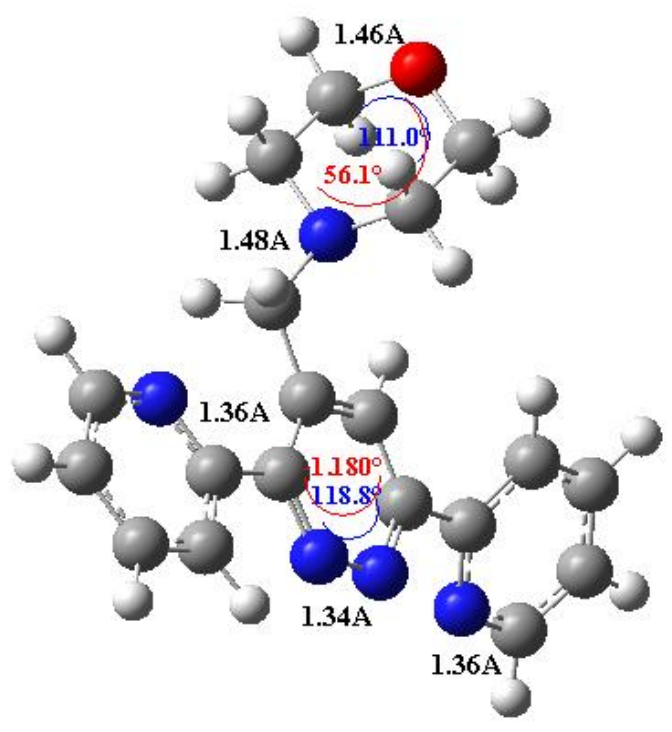

FM2

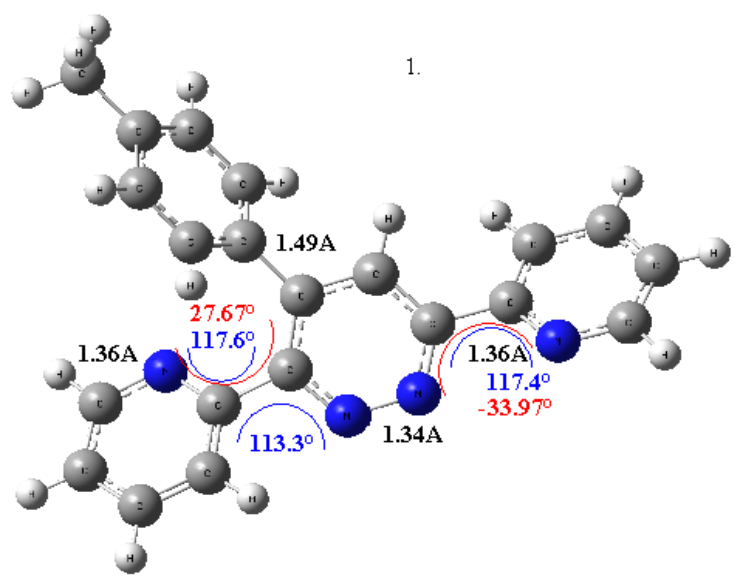

FM3

Figure 5. Optimized molecular structures, selected valence bond angles (blue), dihedral angles (red) and bond lengths (black) of the studied inhibitors (FMs) calculated at B3LYP/6$3 \mathrm{G}(\mathrm{d}, \mathrm{p})$ level.

From the analysis of the theoretical results, it can be concluded that the molecules FM1, FM2 and FM3 have a non-planar structure. 
The HOMO and LUMO molecular orbitals of the synthesized inhibtors (FMs) are presented in Table 6.

Table 6. The HOMO and the LUMO electrons density distributions of the studied inhibitors (FMs) computed at B3LYP/6-31G (d,p) level.

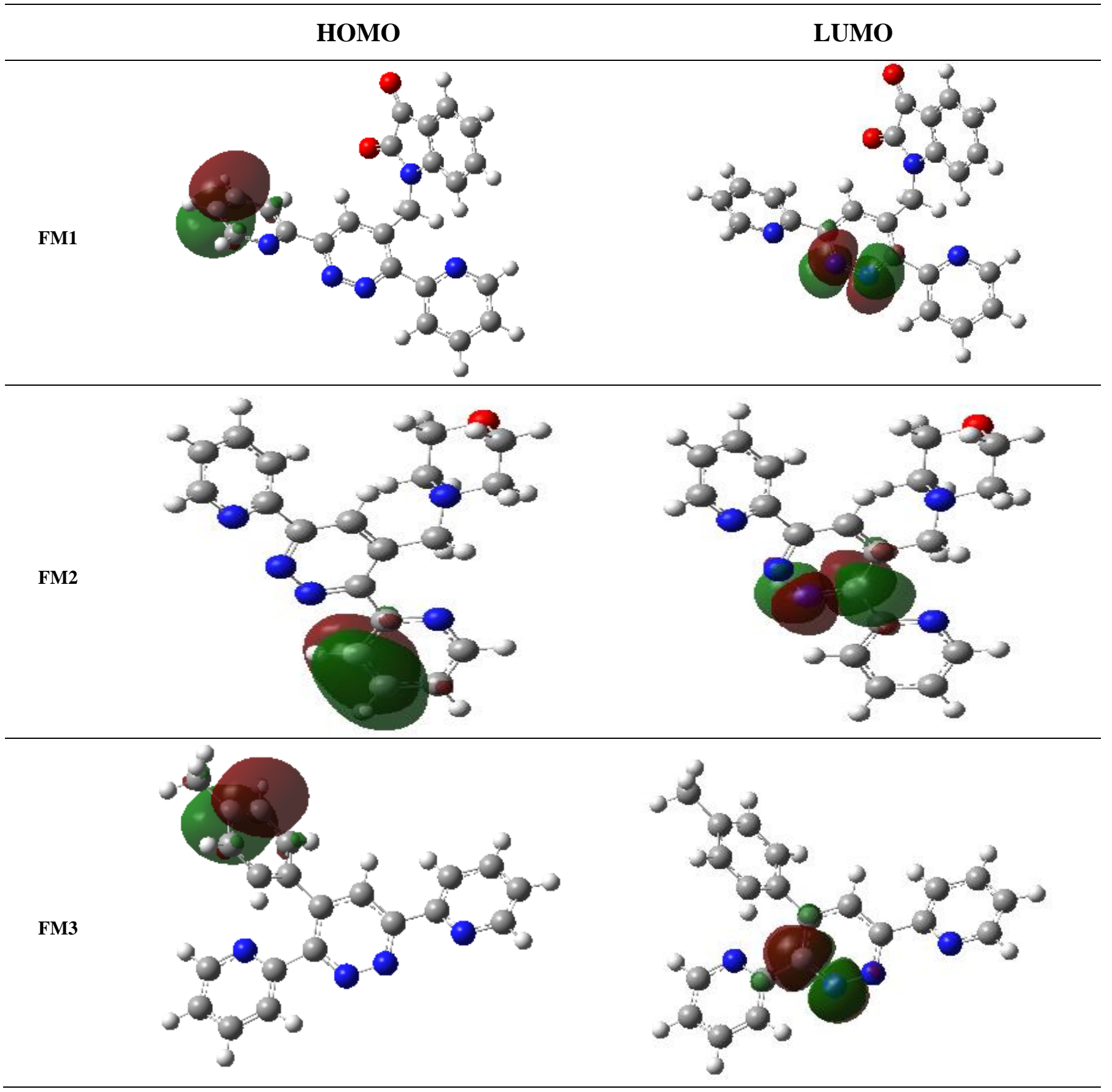

From Table 6, the HOMO orbitals of the synthesized inhibitors are mainly delocalized over the 2-(pyridin-2-yl)pyridine ring.

The inhibition efficiency afforded by the 2-(pyridin-2-yl)pyridine derivatives of the FM1, FM2 and FM3 may be attributed to the presence of electron rich $\mathrm{N}$ atoms. 


\section{Conclusion}

The principal findings of this study can be summarized as follows:

1. A correlation was obtained between the percentage inhibition efficiencies calculated from the electrochemical measurements and weight loss data.

2. Steady-state electrochemical measurements have revealed that the studied compounds FMs act as mixed inhibitors but predominantly cathodic inhibitors for the corrosion of MS in $1.0 \mathrm{M} \mathrm{HCl}$ solutions.

3. The adsorption of FMs compounds on the $\mathrm{MS}$ in $1.0 \mathrm{M} \mathrm{HCl}$ solutions obey the Langmuir adsorption isotherm model.

4. Theoretical in addition experimental studies recommend that the studied FMs compounds act as good inhibitors for the corrosion of $\mathrm{MS}$ in $1.0 \mathrm{M} \mathrm{HCl}$ solutions and that the inhibition efficiency increases by increase in the concentration of the inhibitor. The maximum efficiency values $(\% E$ ) for FM1, FM2 and FM3 were $87 \%, 72 \%$ and $70 \%$, respectively at the maximum concentration of $1.0 \times 10^{-3} \mathrm{M}$.

5. The theoretical results of DFT parameters were compared with the experimental results and it was found that there is a good agreement between them.

\section{References}

1. Ya.G. Avdeev, Int. J. Corros. Scale Inhib., 2018, 7, no. 4, 460-497. doi: 10.17675/ 2305-6894-2018-7-4-1

2. M.A. Quaraishi, J. Rawat and M. Ajmal, J. Appl. Electrochem., 2000, 30, 745.

3. K.R. Ansari, S. Ramkumar, D.S. Chauhan, Md. Salman, D. Nalini, V. Srivastava and M.A. Quraishi, Int. J. Corros. Scale Inhib., 2018, 7, no. 3, 443-459. doi: 10.17675/2305-6894-2018-7-3-13

4. K.C. Emeregül and M. Hayvalí, Corros. Sci., 2006, 48, 797.

5. H. Elmsellem, H. Nacer, F. Halaimia, A. Aouniti, I. Lakehal, A. Chetouani and B. Hammouti, Int. J. Electrochem. Sci., 2014, 9, 5328-5351.

6. K. Rasheeda, V.D.P. Alva, P.A. Krishnaprasad and S. Samshuddin, Int. J. Corros. Scale Inhib., 2018, 7, no. 1, 48-61. doi: 10.17675/2305-6894-2018-7-1-5

7. X. Li, S. Deng, H. Fu and X. Xie, Corros. Sci., 2014, 78, 29.

8. H. Elmsellem, T. Harit, A. Aouniti and F. Malek, Prot. Met. Phys. Chem. Surf., 2015, 51, 873-884.

9. D. Jeroundi, S. Chakroune, H. Elmsellem, E.M. El Hadrami, A. Ben-Tama, A. Elyoussfi and B. Hafez, J. Mater. Environ. Sci., 2017, 5, 1116-1127.

10. S. Lahmidi, A. Elyoussfi, A. Dafali, H. Elmsellem, N.K. Sebbar, L. El Ouasif, A.E. Jilalat, B. El Mahi, E.M. Essassi, I. Abdel-Rahman and B. Hammouti, J. Mater. Environ. Sci., 2017, 8, 225.

11. M. Khasanah, H. Darmokoesoemo, L. Kustyarini, Y. Kadmi, H. Elmsellem and H.S. Kusuma, Results Phys., 2017, 7, 1781-1791. doi: 10.1016/j.rinp.2017.05.015 
12. Z. Tribak, Y.K. Rodi, H. Elmsellem and I. Abdel-Rahman, J. Mater. Environ. Sci., 2018, 9, 334-344.

13. H. Elmsellem, N. Basbas, A. Chetouani and A. Aouniti, Port. Electrochim. Acta, 2014, 32, no. 2, 77-108. doi: 10.4152/pea.201402077

14. H. Elmsellem, K. Karrouchi, A. Aouniti, B. Hammouti, S. Radi, J. Taoufik, M. Ansar, M. Dahmani, H. Steli and B. El Mahi, , Der Pharma Chemica, 2015, 7, 237-245.

15. G. Aziate, H. Elmsellem, N.K. Sebbar and Y. El Ouadi, J. Mater. Environ. Sci., 2017, 8, 3873-3883.

16. H. Elmsellem, A. Aouniti, H. Bendaha, T. Ben hadda, A. Chetouani and I. Warad, Phys. Chem. News, 2013, 70, 84.

17. H. Bendaha, H. Elmsellem, A. Aouniti, M. Mimouni, A. Chetouani and B. Hammouti, Phys.-Chem. Mech. Mater., 2016, 1, 111-118.

18. S. Attabi, M. Mokhtari, Y. Taibi, I. Abdel-Rahman, B. Hafez and H. Elmsellem, J. Bio Tribo Corros., 2019, 5, 2. doi: 10.1007/s40735-018-0193-5

19. R. Chadli, M. Elazouzi, I. Khelladi, A.M. Elhourri and A. Aouniti, Port. Electrochim. Acta, 2017, 35, 65-80.

20. M.Y. Hjouji, M. Djedid, H. Elmsellem, Y. Kandri Rodi, Y. Ouzidan, F. Ouazzani Chahdi, N.K. Sebbar, E.M. Essassi, I. Abdel-Rahman and B. Hammouti, Der Pharma Chemica, 2016, 8, 85-95.

21. A. Aouniti, H. Elmsellem, S. Tighadouini, M. Elazzouzi, S. Radi, A. Chetouani, B. Hammouti and A. Zarrouk, J. Taibah University for Science, 2015, 11, 008. doi: 10.1016/j.jtusci.2015.11.008

22. H. Elmsellem, M.H. Youssouf and A. Aouniti, Russ. J. Appl. Chem., 2014, 8, 744-753.

23. A. Elyoussfi, A. Dafali, H. Elmsellem and H. Steli, J. Mater. Environ. Sci., 2016, 7, 3344-3352.

24. K.F. Khaled, Electrochim. Acta, 2010, 22, 6523.

25. I. Chakib, H. Elmsellem, N.K. Sebbar, S. Lahmidi, A. Nadeem, E.M. Essassi, Y. Ouzidan, I. Abdel-Rahman, F. Bentiss and B. Hammouti, J. Mater. Environ. Sci., 2016, 7, 1866.

26. I.B. Obot and N.O. Obi-Egbedi, Corros. Sci., 2010, 52, 657.

27. R.G. Pearson, J. Amer. Chem. Soc., 1988, 110, 7684-7690.

28. V.S. Sastri and J.R. Perumareddi, Molecular Orbital Theoretical Studies of Some Organic Corrosion Inhibitors, Corrosion, 1997, 53, 617-622. doi: https://doi.org/10.5006/1.3290294

29. I.B. Obot, N.O. Obi-egbedi and S. Umoren, Adsorption Characteristics and Corrosion Inhibitive Properties of Clotrimazole for Aluminium Corrosion in Hydrochloric Acid, Int. J. Electrochem. Sci., 2009, 4, 863-877.

30. A. Zouitini, Y.K. Rodi, H. Elmsellem and H. Steli, J. Mater. Environ. Sci., 2017, 8, no. $11,4105-4116$.

31. H. Ju, Z.-P Kai and Y. Li, Corros. Sci., 2008, 50, 865-871. 